\title{
REPOSITÓRIOS DIGITAIS COMO ESPAÇOS DE MEMÓRIA E DISSEMINAÇÃO DE INFORMAÇÃO
}

\author{
DIGITAL REPOSITORIES AS MEMORY AREAS AND DISSEMINATION OF \\ INFORMATION
}

1 Doutorando em Ciência da Informação (PPGCI/UFPB), Professora da UFRPE e-mail: isledna@gmail.com

2 Doutora em Letras pela UFPB, Professora do PPGCI e do PPGOA/UFPB

E-mail: bernardinafreire@gmail.com

3 Doutora em Letras pela UFPB, Pós-doutoranda em Ciência da Informação (PPGCI/UFPB)

E-mail: nilzasor@yahoo.com.br

\section{ACESSO ABERTO}

Copyright: Esta obra está licenciada com uma Licença Creative Commons Atribuição 4.0 Internacional. $(\mathrm{cc}) \mathrm{EY}$

Conflito de interesses: As autoras declaram que não há conflito de interesses.

Financiamento: Não há.

Declaração de Disponibilidade dos dados: Todos os dados relevantes estão disponíveis neste artigo.

Recebido em: 20/09/2019.

Revisado em: 01/10/2019.

Aceito em: 10/10/2019.

Como citar este artigo:

ALMEIDA, I. R.; OLIVEIRA, B. M. J. F.; ROSA, M. N. B. Repositórios digitais como espaços de memória e disseminação de informação. Informação em Pauta, Fortaleza, v. 4, n. especial, p. 117-131, nov. 2019.

DOI: https://doi.org/10.32810/25253468.ip.v4iEspecial.2019.42609.117-131.
Isledna Rodrigues de Almeida ${ }^{1}$

Bernardina Maria J. F. de Oliveira ${ }^{2}$

iD) Maria Nilza Barbosa Rosa ${ }^{3}$

\section{RESUMO}

Os Repositórios Digitais (RD) surgiram no contexto do movimento do acesso livre à informação, sendo uma forma de disseminação da produção do conhecimento. Dentre os tipos de RD, estão os Repositórios Digitais Institucionais (RDI's), que se tornaram instrumentos populares no meio acadêmico por assegurar o acesso rápido e prático às produções científicas de qualidade associadas à marca institucional, garantir a memória institucional e prover dados para os serviços oferecidos pelas redes sociais acadêmicas, ou seja, são espaços memorialísticos para preservação da informação. Este artigo tem como objetivo realizar uma pesquisa documental para coletar informações sobre os RD, RDI's e Espaços de Memória.

Palavras-chave: Informação. Repositório. Memória Institucional. Espaços de Memória.

\section{ABSTRACT}

Digital Repositories (RD) emerged in the context of the movement of free access to information, being a form of dissemination of knowledge production. Among the types of $\mathrm{RD}$, there are the Institutional Digital Repositories (RDIs) that have become popular tools in academia for ensuring fast and practical access to quality scientific productions, associated with the institutional brand, ensuring institutional memory and still providing data for the services offered by academic social networks, ie, they are memorial spaces for information preservation. This article aims to conduct a desk research to collect information about RD, RDIs and Memory Space. 
Keywords: Information. Repositories.

Institutional Memory. Memory Space.

\section{INTRODUÇÃO}

A informação tem se tornado algo importante para a sociedade. Considerada elemento fundamental da comunicação, ela atinge os diferentes tipos de pessoas, as diversas classes sociais, faixas etárias, graus de escolaridade e identidades culturais. Para cada informação, de cunho científico ou não, existe um usuário interessado em utilizá-la, a fim de realizar alguma tarefa, obter conhecimento e tomar decisões. Porém, quando o usuário busca essa informação, encontra algumas dificuldades na seleção e recuperação, devido à grande quantidade de informação disponível, seja virtual ou impressa, e devido à instantaneidade com que essas informações se modificam. Dessa forma, se torna primordial, para qualquer usuário, saber quais atendem as suas necessidades e identificar onde buscá-las, seja para solucionar uma curiosidade, aprimorar seus conhecimentos ou embasar uma pesquisa.

Existem fontes e recursos informacionais disponíveis de forma oral, impressa, digital e multimídia, que possuem funções e conteúdos distintos. Dentre as diversas fontes de informação estão os Repositórios Digitais Institucionais (RDI). Eles surgiram como uma ferramenta que possibilita o agrupamento de diversos tipos de produção e a disponibilização democrática dessa produção para a academia e a sociedade em geral, fazendo jus à responsabilidade social de contribuir com o desenvolvimento científico do país.

Este artigo propõe analisar o conceito de repositório digital e seus tipos, entre eles, o RDI, e a sua utilização como espaço memorialístico. Trata-se de um artigo elaborado utilizando as técnicas da pesquisa exploratória e bibliográfica, além do método de investigação de análise documental. O levantamento bibliográfico foi realizado na literatura a respeito dos conceitos de repositórios e memória aqui apresentados.

No entendimento de Cervo e Bervian (2002, p. 69), “os estudos exploratórios não elaboram hipóteses a serem testadas no trabalho, restringindo-se a definir objetivos e buscar mais informações sobre determinado assunto de estudo". 
As fontes de estudos para elaboração do artigo são vastas. Livros, artigos consagrados e publicados permitiram a utilização da pesquisa bibliográfica, que "[...] tanto pode ser um trabalho independente como se constituir no passo inicial de outra pesquisa" (ANDRADE, 2003, p. 26).

Na compreensão de Gil (2002, p. 44), a pesquisa bibliográfica “é desenvolvida com base em material já elaborado, constituído principalmente de livros e artigos científicos [...]. Boa parte dos estudos exploratórios pode ser definida como pesquisa bibliográfica".

Os repositórios digitais tornaram-se instrumentos populares no meio acadêmico por garantirem o acesso ágil às produções científicas de qualidade associados à marca institucional. Trabalham com a preservação da informação em longo prazo, garantem a memória institucional e são provedores de dados para os serviços oferecidos pelas redes sociais acadêmicas.

\section{REPOSITÓRIOS DIGITAIS}

Com o surgimento da Internet na segunda metade do século XX, houve muitas mudanças significativas no modo de comunicação e no fluxo informacional, possibilitando a transmissão informacional mais ampla, mais rápida e atingindo uma maior quantidade de usuários. Essas mudanças atuaram de forma pragmática no âmbito acadêmico, permitindo o aumento da disseminação da produção científica para todos os indivíduos.

Para Campello, Cendón e Kremer (2000), as tecnologias de informação e comunicação causaram mudanças nos canais formais e informais, que se modificaram, ampliaram e diversificaram, tornando a transmissão da informação mais rápida e eficiente.

Neste contexto, as fontes de informação aparecem como uma ferramenta de auxílio para recuperação de informações para usuários inseridos em diferentes contextos. "Uma fonte de informação é qualquer recurso que responda a uma demanda de informação por parte dos usuários, incluindo produtos e serviços de informação, pessoas ou rede de pessoas, programas de computador, etc." (BIREME, 2001, p. 7).

Brum e Barbosa (2009, p. 60) dividem as fontes de informação na Internet em diversos setores: 
a) Listas de discussão,

b) Correio eletrônico (e-mail),

c) Informativos via correio eletrônico (newsletter),

d) Informativos comerciais via correio eletrônico (e-mail marketing),

e) Salas de bate-papo virtual (chat),

f) Mensageiros instantâneos (instant messengers),

g) Sítios de busca ou ferramentas de busca,

h) Intranets, extranets, os próprios sítios disponíveis na web.

Essas fontes e recursos informacionais estão disponíveis na forma oral, impressa, digital e multimídia, que possuem funções diferentes e se diferenciam por meio do seu conteúdo, que consequentemente se direcionam a usuários específicos. Dentre essas fontes, têm-se os Repositórios Digitais (RD).

Na visão de Murakami e Fausto (2013), os repositórios digitais representam a rápida evolução da comunicação científica no ambiente virtual. Essa evolução partiu de iniciativas como a Iniciativa Arquivos Abertos (Open Archive Initiative - OAI) e o Movimento de Acesso Aberto (Open Access Movement - OAM), "visando promover modelos eficientes de armazenamento, disseminação, visibilidade e acesso aos conteúdos científicos”. (MURAKAMI; FAUSTO, 2013, p. 186).

Viana e Arellano (2006, p.2) conceituam repositórios digitais como forma de armazenamento de objetos digitais que têm a capacidade de manter e gerenciar material por longos períodos de tempo e prover o acesso apropriado. Desse modo, os repositórios incentivam e gerenciam a publicação pelo pesquisador, utilizam tecnologia aberta e podem ser acessados por diversos provedores de serviços nacionais e internacionais.

Repositórios são definidos como um "sistema de informação responsável por gerir e armazenar material digital" (FERREIRA, 2006, p. 71).

Para Costa (2008, p. 225) os repositórios representam uma espécie de revolução de disseminação da pesquisa, pois o

[...] autoarquivamento em repositórios institucionais ou temáticos de trabalhos já publicados ou aceitos para publicação em periódicos ou outros veículos de comunicação. Isto é, de trabalhos já avaliados por pares. [...] maximiza o acesso, a visibilidade e o progresso da pesquisa. Não se trata de substituir nenhum outro estágio do processo de comunicação, principalmente, o estágio da publicação formal, mas de uma instância eficaz de disseminação ampla e irrestrita, livre de barreiras de preço e de permissão de uso. Desse modo, os repositórios devem conter uma cópia de todo trabalho publicado ou aceito para 
publicação em periódicos, livros ou outro veículo, em ambiente interoperável e aberto.

Segundo Leite (2009, p. 22), os repositórios têm como finalidade, além de gerenciar a informação científica, [...] melhorar a comunicação científica interna e externa à instituição; maximizar a acessibilidade, o uso, a visibilidade e o impacto da produção científica da instituição; retroalimentar a atividade de pesquisa científica e apoiar os processos de ensino e aprendizagem; apoiar as publicações científicas eletrônicas da instituição; contribuir para a preservação dos conteúdos digitais científicos ou acadêmicos produzidos pela instituição ou seus membros; contribuir para o aumento do prestígio da instituição e do pesquisador; oferecer insumo para a avaliação e monitoramento da produção científica; reunir, armazenar, organizar, recuperar e disseminar a produção científica da instituição.

Os RDs atendem determinado público alvo, e, de acordo com Sayão e Sales (2015), existem diferentes tipos de RD para a hospedagem de objetos digitais, como:

a) Repositórios temáticos ou disciplinares: agregam trabalhos de uma área específica do conhecimento, ou seja, particularizam a produção intelectual em função das áreas do conhecimento;

b) Repositório de teses e dissertações: lidam exclusivamente com teses e dissertações defendidas de programas de pós-graduação das diversas áreas do conhecimento;

c) Repositório Institucional (RI) ou Repositório Digital Institucional (RDI): voltados à produção intelectual de uma instituição, especialmente universidades e institutos de pesquisa.

d) Repositórios Governamentais - Repositórios de dados apoiados por agências governamentais. Por exemplo: DATA.GOV (www.data.gov).

Nesse artigo serão abordados os Repositórios Digitais Institucionais (RDI), definidos por Leite (2012) como a “[...] reunião, armazenamento, organização, preservação, recuperação e, sobretudo, a ampla disseminação da informação cientifica produzida na instituição".

Em relação aos RDI, o Instituto Brasileiro de Informação em Ciência e Tecnologia (2012, p. 7) destaca que eles "constituem de fato inovação no sistema de comunicação da ciência e no modo como a informação - aquela que alimenta e resulta das atividades acadêmicas e científicas - é gerenciada". 
$\mathrm{Na}$ visão de Arellano (2008), os RDI’s são “arquivos digitais de produtos intelectuais de caráter acadêmico e acessíveis aos usuários, interoperáveis e respaldados por alguma instituição que garante sua preservação em longo prazo".

Os repositórios digitais surgiram como uma resposta à industrialização da comunicação científica, que dificulta o progresso científico. Além dos movimentos de acesso livre, citados por Bomfá et al. (2008 apud Avila et al., 2017), tais como as Declarações de Budapest e Berlimi, Open Archives Initiative (OAI) ${ }^{\mathrm{ii}}$ e o Manifesto Brasileiro de apoio ao acesso livre à informação científicaiii, três outros fatores contribuíram de forma significativa para o crescimento do número de repositórios (AVILA et al., 2017):

1. Primeiro, a modificação em relação ao uso de novas formas de direitos autorais para publicação das obras, pois poderia representar uma ameaça ao livre acesso. A licença Creative Commons (http://creativecommons.org/), por exemplo, permite maior flexibilidade para copiar e reusar diferentes tipos de trabalhos intelectuais sob determinadas condições.

2. Segundo, o desenvolvimento tecnológico é importante para viabilizar novos repositórios que utilizam softwares de código aberto, de caráter regulatório e legal, e de sustentabilidade, que impactam a criação, manutenção e uso de repositórios de objetos de aprendizagem.

3. Terceiro, a adoção por vários países, inclusive pelo Brasil, de políticas para o depósito, em repositórios institucionais, dos trabalhos científicos produzidos em instituições de ensino e pesquisa, o que incentiva tanto a criação de repositórios quanto o depósito de obras neles.

Esses fatores foram verificados na maioria dos repositórios institucionais dos países ibero-americanos (COCCO; RODRIGUES, 2014).

Entre as características destes arquivos/repositórios de acesso aberto, estão (Moreno, 2006):

i) Processo automático de comentários;

ii) Geração de versões de um mesmo documento: uma vez que o documento seja comentado, o autor pode gerar novas versões do mesmo, atualizando a informação;

iii) Heterogeneidade dos formatos contemplados no sistema: inicialmente concebido para servir à divulgação de pré-prints1, os arquivos de acesso 
aberto ampliaram sua tipologia de documentos que podem ser arquivados;

iv) Autoarquivamento, que devolve o direito ao autor de enviar seu texto para publicação onde este decidir e sem intermediação de terceiros: os documentos eletrônicos são inteiramente gerenciados pelos cientistas e são suficientemente flexíveis tanto para coexistir com os sistemas de publicação tradicional como para auxiliar os editores a se envolverem com algo mais próximo das necessidades dos pesquisadores, e interoperabilidade no funcionamento dos arquivos de acesso aberto: os arquivos/repositórios de acesso aberto envolvem um conjunto mínimo de metadados, um tipo de arquitetura subjacente ao sistema, com abertura para a criação de serviços de bibliotecas digitais compartilhados e medidas de uso e de citação.

Os RDI's têm como objetivo principal o aumento da divulgação das pesquisas e produções intelectuais das instituições de ensino e pesquisa, alcançando, assim, a "[...] oportunidade de se fortalecerem institucionalmente a partir da visibilidade de sua produção acadêmica organizada e disponível, como um retrato fiel de sua instituição, a partir de seu repositório institucional”. (SAYÃO et al., 2009, p. 19).

Conhecer fontes confiáveis, especializadas ou não, e aplicar critérios de seleção, pode garantir a qualidade da informação a ser recuperada. Tanto no caso da pesquisa científica, como empresarial ou comercial, as informações recuperadas devem ser de qualidade, ter confiabilidade e credibilidade, contribuindo para a excelência no repasse de informação.

\section{ESPAÇOS MEMÓRIALÍSTICOS}

Espaços ou lugares de memória são definidos por Nora (1997, p. 16) como: “toda a unidade significativa, de ordem material ou ideal, da qual a vontade dos homens ou o trabalho do tempo fez um elemento simbólico do patrimônio da memória de uma comunidade qualquer".

Alguns problemas podem ocorrer com esses lugares de memória, dentre eles, a perda, alteração, dano, destruição e até mesmo esquecimento. Um dos meios mais 
produtivos de evitar alguns desses problemas é a escrita. Ela permanece inalterada por muito tempo, mesmo depois da morte de seu autor.

A memória só existe com os artifícios da linguagem e escrita, pois não é possível reter ou recuperá-la sem suporte técnico. A memória não pode existir como algo puramente cerebral, e o passado não pode sobreviver sem os suportes que nos inscrevem em nossas culturas e tradições (FERREIRA; AMARAL, 2004).

Assmann (2001) propõe quatro estágios evolutivos e, atualmente, simultâneos da escrita: a escrita iconográfica, a alfabética, a analógica do vestígio e a digital, confirmando sua importância como suporte da memória.

Os tempos da memória são marcados pela passagem entre a oralidade e a escrita, e são divididos em cinco períodos (LE GOFF, 1990):

1) a memória étnica nas sociedades sem escrita, consideradas selvagens;

2) o desenvolvimento da memória, da oralidade à escrita, da Pré-história à Antiguidade;

3) a memória medieval, em equilíbrio entre o oral e o escrito;

4) os progressos da memória escrita, do século XVI aos nossos dias; e

5) os desenvolvimentos atuais da memória.

Com os progressos da memória escrita, os suportes continuaram a se renovar, até se tornarem acessíveis por meios eletrônicos, impulsionados pelas Tecnologias Digitais da Informação e Comunicação. O conteúdo informativo, presente em um meio eletrônico, disponível através do uso de um computador conectado à Internet, pode ser acessado a qualquer hora, de qualquer lugar.

Com o avanço das Tecnologias Digitais da Informação e Comunicação e a velocidade com que as informações estão sendo propagadas, o tema memória vem ganhando destaque. De acordo com Oliveira e Rodrigues (2012):

As limitações da memória humana levaram o homem a buscar em recursos externos, as chamadas memórias artificiais, a compensação para o esquecimento. A necessidade de possibilitar o acesso aos registros por ele produzidos ao decorrer do tempo levou à criação das chamadas instituições de memória que deveriam preservar os registros do conhecimento humano nas suas mais diversas formas de materialização [...] (OLIVEIRA; RODRIGUES, 2012, p. 495).

Na era das Tecnologias Digitais da Informação e Comunicação, um dos pontos fundamentais é saber o que será armazenado e o que será descartado da memória. 
Antes, tudo que se via e se produzia eram fontes de informações. Atualmente, há uma seleção do que deve ser lembrado e o que deve ser esquecido.

0 interesse pela propriedade da memória é semelhante à necessidade de ter acesso à informação. Com a capacidade de reter a memória, há uma facilidade na recuperação da informação nela contida, que também se pode designar como a própria memória, pois a informação/memória continuará intacta, disponível para uso a qualquer tempo.

Segundo Monteiro, Carelli, Pickler (2006 p. 115), o termo memória “[...] foi associado, especialmente na arquivologia, biblioteconomia e museologia, ao conjunto das informações registradas, isto é, aos documentos e representações que podem ser consultados, servindo de memória social ou memória de longo prazo".

Conforme citado por Indolfo (2007), a construção da memória pode ser definida como a estruturação da lembrança através dos documentos.

Lembrar é uma necessidade prática da vida cotidiana de qualquer pessoa ou instituições, é o resultado da necessária continuidade da vida dos indivíduos como organismos, isto é, a continuidade de cada uma de suas ações. Em qualquer época, tanto na administração quanto nas empresas ou nas profissões liberais, uma sucessão ou uma transferência de atribuições é acompanhada pela transmissão dos registros e dos documentos, numa palavra: dos arquivos. (DELMAS, 2006, p. 27 apud SILVA E GODOY, 2017, p. 9).

A produção científica compõe o acervo da memória social da comunidade científica, e se verte numa memória própria a esse grupo: a memória científica. Por meio dessa memória, a ciência se preserva com a possibilidade de ser acessada em espaços de memória, reproduzidos por suportes e lugares de memória.

Com o surgimento da era da informação e o crescimento das ferramentas tecnológicas de comunicação e entretenimento - redes sociais, acessibilidade e portabilidade de informações -, se proporcionou ao cidadão a utilização dos meios eletrônicos de informação, tanto para a busca de informações do dia-a-dia, como para informações de caráter técnico-científico. Após o evento das publicações eletrônicas, a comunicação acadêmica passou a contar com os repositórios como novo instrumento para disseminação da informação científica.

Essa produção científica está voltada para as instituições nas formas de lidarem com a informação, nas ferramentas utilizadas, em suas práticas de gestão da informação 
e de gestão do conhecimento no âmbito institucional. Essas novas abordagens e formas de tratar a informação institucional dão ênfase aos novos meios de aplicação e manuseio das inovações tecnológicas de organizações oriundas da internet. Os RDIs são utilizados para disseminação democrática, em rede, da produção do conhecimento.

Nora (1993) explica que os lugares da memória surgem como fruto do advento e do avanço tecnológico, os quais devem ser gerenciados como suportes da memória coletiva. Nessas condições, tem-se que os repositórios institucionais servem como auxílio na democratização de acesso às informações na sociedade moderna. Um grande salto qualitativo para a democratização do acesso ao conhecimento se dá quando a rede permite um alcance mundial de trocas de conhecimento científico (NORA, 1993).

Dessa forma, a internet se torna uma ferramenta de guarda da nossa memória, que possibilita um mecanismo para recuperá-la, construir e conservar, visto que é a ferramenta principal para o uso dos RI. Por isso, os resultados das pesquisas podem ser divulgados e consultados, já que os RI representam uma forma de preservar a memória coletiva da instituição e de organização do conhecimento para a memória científica.

Eles também constituem lugares onde se gerencia a memória científica. Assim, as instituições inseridas na sociedade, como lugares de memória social registrada, agem, reagem e interagem às tecnologias e à ciência, constituindo a exomemória de diversas instituições (GARCÍA GUTIÉRREZ, 2001).

Segundo Bosi (2012), os meios eletrônicos de informação foram inventados para poupar tempo das pessoas, algo sempre muito exigido na era das tecnologias de informação e comunicação. Os meios eletrônicos aceleram os movimentos de transmissão de sinais até o limite da instantaneidade.

Como preceitua Burke (2003, p. 127), “À medida que aumentavam de volume, os registros passaram a precisar de repositórios especiais, os arquivos, com guardiões especiais".

Segundo Assmann (2011), a memória não é considerada como vestígio ou armazenamento, mas como uma massa plástica constantemente reformulada sob as diferentes perspectivas do presente, pois se pode pensar na coexistência de diversas formas de se conceber e usar a memória atualmente.

Para Bosi (2012), a memória, saltando sobre a cronologia, recupera o tempo perdido, enquanto anula o passado-como-passado e o chama para a consciência viva do presente. 
De acordo com Miranda, Galindo e Vila Nova (2011), a memória institucional tem, como papel fundamental, contribuir para o resgate e preservação da memória de uma organização, colaborando para a construção da identidade coletiva, que se forma a partir da convergência de esforços para realização do interesse comum, onde a história de cada um se confronta e se enriquece com a história de outros.

A memória institucional tem a possibilidade de ser preservada quando iniciativas de institucionais buscam projetos de valorização dessa produção como patrimônio da humanidade, como é o caso singular da Biblioteca Digital Mundial e dos Repositórios Institucionais (DODEBEI, 2009).

A memória institucional ou o centro de memória possui diversos elementos que os consolidam e os definem como memórias. Entre eles, se destacam: histórico institucional/local; identidade da instituição; formação/definição/consolidação da instituição; geração de informação decisional; suas relações sociais; e a gestão da informação e do conhecimento.

Dessa forma, as pesquisas relatam que uma das funções da Memória institucional, quando bem documentada e organizada, é garantir a perpetuação da memória para as próximas gerações e torná-la mais um instrumento que agregue valor a instituição. Por isso, proporciona às organizações um melhor entendimento de suas origens e de sua história e um senso importante de identidade.

Segundo Rueda et al. (2011), a partir de 1970 se valorizou a memória institucional com uma maior utilização de tecnologias que proporcionam aos usuários uma utilização rápida das informações, pois as instituições “[...] produzem ao longo de sua trajetória uma vasta quantidade de documentos fundamentais para a preservação da Memória Institucional (RUEDA et al., 2011, p.78).

Além disso, Ruedas et al. (2001) defendem que a preservação desta memória garante informações confiáveis sobre a entidade, que podem ser utilizadas nas tomadas de decisão diariamente, conseguindo, desta maneira, manter uma coerência dos atos institucionais.

Os repositórios digitais institucionais promovem a valorização, reconstrução e divulgação da memória institucional das universidades. A cada dia essas ferramentas se integram no cotidiano dos ambientes acadêmicos, contribuindo para a construção do conhecimento e satisfação das necessidades informacionais dos usuários. 
Desta forma, os repositórios institucionais estão no caminho de retratar a trajetória experimentada pela instituição, pois permitem recuperar a informação com relação ao registro e à busca da informação.

\section{CONSIDERAÇÕES FINAIS}

Os Repositórios Digitais têm se tornado instrumentos populares no meio acadêmico por garantirem o acesso rápido às produções científicas de qualidade associadas à marca institucional, por preservar a informação ao longo prazo, garantir a memória institucional e por serem provedores de dados para os serviços oferecidos pelas redes sociais acadêmicas.

Por meio dos RDI's é possível recuperar informações que satisfaçam as necessidades dos usuários e disseminar o conhecimento científico produzido pela comunidade acadêmica.

Alimentar os RDI's com publicações científicas contribui para reunir, organizar e compor o acervo da memória institucional. Ressalta-se ainda a importância dos repositórios institucionais pelo potencial que apresentam como ferramenta de acesso aberto que permite organizar, disseminar e preservar a memória institucional. Assim, os RDIs podem colaborar com uma das missões da universidade, que é ser um centro de produção intelectual, devendo, assim, preservar sua memória e contribuir para o avanço da ciência, tecnologia e humanidade.

\section{REFERÊNCIAS}

ARELLANO, M. A. Critérios para a preservação digital da informação científica. 2008. 356 f. Tese (Doutorado em Ciência da Informação) - Universidade de Brasília, Brasília, 2008. Disponível em: repositorio.bce.unb.br/handle/10482/1518. Acesso em: 10 out. 2019

ASSMANN, A. T. Locais. In: ASSMANN, A. T.

Espaços de recordação: formas e transformações da memória cultural. Campinas: Unicamp, 2001
ÁVILA, B. T.; SILVA, M.; CAVALCANTE, L. Uso de repositórios digitais como fonte de informação por membros das universidades federais brasileiras. Informação \&

Sociedade, João Pessoa, v. 27, n. 3, p. 97-120, set./dez. 2017. Disponível em:

http://www.periodicos.ufpb.br/ojs2/index.p hp/ies/article/view/31514/pdf. Acesso em: 10 out. 2019

BIREME. Guia 2001 de desenvolvimento da Biblioteca Virtual em Saúde. São Paulo, 2001. Disponível em: 
http://bvsms.saude.gov.br/bvs/publicacoes /guia_tecnologias_modelo_bvs.pdf. Acesso em: 14 ago. 2019.

BOSI, A. Considerações sobre o tempo e a informação. Seminário "Internet, mente e sociedade”. São Paulo: IEA-USP, 1995.

Disponível em:

http://200.144.254.127:8080/textos/bosiint ernet.pdf. Acesso em: 12 ago. 2019.

\section{BUCKLAND, M.K. Information as thing.}

Journal of the American Society for Information Science, v. 45, n. 5, p. 351- 360, 1991.

BRUM, Marco Antonio Carvalho; BARBOS, Ricardo Rodrigues. Comportamento de busca e uso da informação: um estudo com alunos participantes de empresas juniores. Perspect. ciênc. inf., Belo Horizonte, v. 14, n. 2, p. 52-75, 2009. Disponível em: http://www.scielo.br/scielo.php?script=sci_ arttext\&pid=S141399362009000200005\&lng=en\&nrm=iso. Acesso em: 11 out. 2019. DOI: http://dx.doi.org/10.1590/S141399362009000200005

BURKE, P. Uma história social do conhecimento: de Gutemberg a Diderot. Rio de Janeiro: Jorge Zahar, 2003. 241 p. ISBN 85-7110-711-4

CAMPELLO, B. S.; CENDÓN, B. V.; KREMER, J. $M$. (org.). Fontes de informação para pesquisadores e profissionais. Belo Horizonte: Ed. UFMG, 2000.

CERVO, Amado Luiz; BERVIAN, Pedro Alcino. Metodologia científica. 5. ed. São Paulo: Pearson Prentice Hall, 2002.

COCCO, A. P.; RODRIGUES, R. S. Repositórios institucionais de acesso aberto: Cenário nos países Ibero-Americanos. Informação e

Sociedade, v. 24, n. 2, p. 111-120, 2014.

COSTA, S. Abordagens, estratégias e ferramentas para o acesso aberto via periódicos e repositórios institucionais em instituições acadêmicas brasileiras. Liinc em Revista, Rio de Janeiro, v.4, n.2, p. 218-232, set. 2008. Disponível em:

http://repositorio.unb.br/handle/10482/16 048. Acesso em: 10 jul. 2019.

DODEBEI, V. Repositórios institucionais: por uma memória criativa no ciberespaço. In: SAYÃO, L. et. al. (org). Implantação e gestão de repositórios institucionais: políticas, memória, livre acesso e preservação. Salvador: EDUFBA, 2009. 365 p. ISBN 97885-232-0655-0.

DODEBEI, V.; GOUVEIA, I. Memória do futuro no ciberespaço: entre lembrar e esquecer. DataGramaZero: Revista de Ciência da Informação. Brasília, v. 9, n. 5, out. 2008.

FERREIRA, J.; AMARAL, A. Memória eletrônica e desterritorialização. Revista Sociologia, n. 4, p. 137-166, abr. 2004

FERREIRA, M. Introdução à preservação digital: conceitos, estratégias e actuais consensos. Universidade do Minho: Escola de Engenharia, 2006. Disponível em: http://eprints.rclis.org/archive/00007977/ 01/livro.pdf. Acesso em: 1 ago. 2019

GARCÍA GUTIÉRREZ, A. Redes digitales y exomemoria. In: CONGRESO IBÉRICO: LA SOCIEDAD DE LA COMUNICACIÓN, 2001, Málaga. Anais eletrônicos [...]. Málaga: [s.n.], 2001. Disponível em: https://dialnet.unirioja.es/servlet/articulo?c odigo $=758654$

Acesso em: 21 jul. 2019. 
GIL, Antônio Carlos. Como elaborar projetos de pesquisa. 4. ed. São Paulo: Atlas, 2002.

INDOLFO, A. C. Gestão de documentos: uma renovação epistemológica no universo da arquivologia. Arquivistica.net [on-line], Rio de Janeiro, v. 3, n. 2, p. 28-60, jul./dez. 2007. Disponível em: http://basessibi.c3sl.ufpr.br/brapci/index.p hp/article/view/0000005190/add166474ac 417 c72d0570eb86fb185d. Acesso em: 20 abr. 2017.

INSTITUTO BRASILEIRO DE INFORMAÇÃO EM CIÊNCIA E TECNOLOGIA (IBICT). RI: repositórios institucionais: boas práticas para a construção de repositórios institucionais da produção científica. Brasília: IBICT, 2012. Disponível em: http://livroaberto.ibict.br/bitstream/1/703 /1/BoasprAticasparaconstruCAorepositorios institucionaisdaproduCAocientifica.pdf. Acesso em: 04 ago. 2019.

LE GOFF, J. História e memória. Campinas, SP: Ed. da Unicamp, 1990. 553 p. (Coleção Repertórios) ISBN 85-268- 0180-5

\section{LEITE, F. C. L. Como gerenciar e ampliar a visibilidade da informação científica} brasileira: repositórios institucionais de acesso aberto. Brasília: Ibict, 2009. 120 p.

LEITE, F. et al. Boas práticas para a construção de repositórios institucionais da produção científica. Brasília: IBICT, 2012. Disponível em: http://livroaberto.ibict.br/handle/1/703. Acesso em: 27 jul. 2019.

MIRANDA, M.; GALINDO, M.; VILA NOVA, S. Política de Preservação Digital nos Repositórios Institucionais de Acesso Livre: o caso das Instituições de Ensino Superior no Brasil. In: ENCONTRO NACIONAL DE CIÊNCIA DA INFORMAÇÃO, 12, 2011,
Brasília. Anais [...]. Brasília: ENANCIB, 2011. Disponível em: http://enancib.ibict.br/index.php/enancib/e nancibXII/paper/view/1028

Acesso em: 10 out. 2019

MONTEIRO, Silvana; CARELLI, Ana; PICKLER, Maria Elisa. Representação e memória no ciberespaço. Ci. Inf., Brasília, v. 35, n. 3, p. 115-123, dez. 2006 . Disponível em http://www.scielo.br/scielo.php?script=sci_ arttext\&pid=S0100$19652006000300011 \& \operatorname{lng}=e n \& n r m=i s o$. Acesso em: 15 ago. 2019. DOI: http://dx.doi.org/10.1590/S010019652006000300011.

MORENO, Fernanda Passini; LEITE, Fernando César Lima; ARELLANO, Miguel Ángel Márdero. Acesso livre a publicações e repositórios digitais em ciência da informação no Brasil. Perspect. ciênc. inf., Belo Horizonte, v. 11, n. 1, p. 8294, abr. 2006. Disponível em: http://www.scielo.br/scielo.php?script=sci_ arttext\&pid=S141399362006000100007\&lng=en\&nrm=iso. Acesso em: 10 out. 2019. DOI: http://dx.doi.org/10.1590/S141399362006000100007.

OLIVEIRA, E. B. RODRIGUES, G. M. O Conceito de memória na Ciência da Informação: análise das teses e dissertações dos programas de pós-graduação. In: MARIZ, A. C. A.; JARDIM, J. M.; SILVA, S. C. de A. (org.). Novas dimensões da pesquisa e do ensino da Arquivologia no Brasil. Rio de Janeiro: Móbile, 2012. p. 495-511

Disponível em: http://revista.ibict.br/liinc/article/view/33 02 Acesso em: 15 set. 2019

MURAKAMI, T. R. M.; FAUSTO, S. Panorama atual dos Repositórios Institucionais das Instituições de Ensino Superior no Brasil. Incid, São Paulo, v. 4, n. 2, p.185-201, set. 
2013. Disponível em:

http://www.revistas.usp.br/incid/article/vi ew/69327. Acesso em: 18 jul. 2019.

NORA, P. Entre memória e história: a problemática dos lugares. Projeto História, n. 10. São Paulo: PUC/SP, 1993.

RUEDA, V. M. S.; FREITAS, A.; VALLS, V. M. Memória Institucional: uma revisão de literatura. CRB-8 Digital, São Paulo, v. 4, n. 1, p. 78-89, abr. 2011. Disponível em: http://www.brapci.inf.br/index.php/res/do wnload/46587. Acesso em: 11 ago. 2019.

SAYÃO, Luis Fernando; MARCONDES, Carlos Henrique. Introdução: repositórios institucionais e livre acesso. In: SAYÃO, Luís et al. (org.). Implantação e gestão de repositórios institucionais: políticas, memória, livre acesso e preservação. Salvador: EDUFBA, 2009.

SAYÃO, Luís Fernando; SALES, Luana Farias. Guia de Gestão de Pesquisa para bibliotecários e pesquisadores. Rio de Janeiro: CNEN, 2015.

SILVA, Daniele Augusta dos Santos; GODOY, Emília Soares da Silva. 0 arquivo na construção da memória institucional. RBBD. Revista Brasileira de Biblioteconomia e Documentação, São Paulo, v. 13, p. 27672778, dez. 2017. ISSN 1980-6949. Disponível em:

https://rbbd.febab.org.br/rbbd/article/view /912/971. Acesso em: 11 out. 2019.

THIESEN, I. Memória institucional. João Pessoa: Editora da UFPB, 2013. 312 p.

VIANA, C. L. M.; ARELLANO, M. A. M. Repositórios Institucionais baseados em Dspace e Eprints e sua visibilidade nas instituições acadêmico-científicas. In: Seminário Nacional de Bibliotecas Universitárias, 2006, Salvador. Anais. Salvador: UFBA, 2006. p. 1-15.

\section{NOTAS}

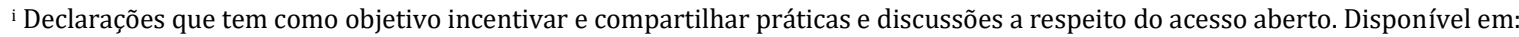
http://www.budapestopenaccessinitiative.org/read e https://openaccess.mpg.de/Berlin-Declaration

ii Open Archives Initiative (OAI) - iniciativa que estabelece, além de padrões de interoperabilidade, alguns princípios e ideais, como o uso de software open source e o acesso livre à informação.

iii Manifesto Brasileiro de apoio ao acesso livre à informação Científica Disponível em: http://livroaberto.ibict.br/Manifesto.pdf
} 